\title{
Inclusão escolar e neoliberalismo: a quem serve a lógica da normalização, performance e competição?
}

\author{
School inclusion and neoliberalism: who serves the logic of \\ normalization, performance and competition?
}

\section{Inclusión escolar y neoliberalismo: ¿a quién sirve la lógica de normalización, desempeño y competencia?}

\author{
Francélio Ângelo de Oliveira'
}

https://orcid.org/0000-0002-8|33-753|

Adéle Cristina Braga Araujo²

https://orcid.org/0000-0002-0386-4053

\begin{abstract}
Resumo: Este artigo, de natureza bibliográfica, pretende discutir a inclusão escolar em interface com as determinações da racionalidade neoliberal. Para tanto, ancorou-se nas discussões trazidas por autores como Silveira Bueno (2004), Rigo (2018) e Laval (2019), dadas as suas contribuições ao debate acerca da história da escolarização das pessoas com deficiência, às reflexões sobre o pensamento neoliberal e à relação entre inclusão escolar e neoliberalismo. Os resultados revelam que a inclusão escolar, na perspectiva neoliberal, funciona como dispositivo de ajustamento e normalização para a fabricação de características individuais adequadas à inserção dos indivíduos na arena competitiva do mercado. No entanto, entende-se ser imprescindível se contrapor à lógica neoliberal, de modo que a escola comum seja compreendida como um espaço de todos e para todos, que elimine o dualismo educacional que seleciona e exclui. Nesse sentido, é necessário ultrapassar os limites do contexto neoliberal para se alcançar efetivamente a escola inclusiva.
\end{abstract}

Palavras-chave: Escolarização das pessoas com deficiência. Alinhamento Mercadológico. Contexto Neoliberal.

Abstract: This article, which has a bibliographical character, aims to discuss the school inclusion in relation to the determinations of the neoliberal rationality. Thus, discussions developed by authors as Silveira Bueno (2004), Rigo (2018) and Laval (2019) were used because of their contributions to the debate about the schooling history of people with some deficiency, in addition to the reflections about the neoliberal thought and the relation between school inclusion and neoliberalism. The results reveal that the school inclusion, under the neoliberal perspective, functions as adjustment and normalization device towards the development of individual

\footnotetext{
I Doutor em Educação pela Universidade Federal do Ceará (UFC). Professor do Instituto Federal de Educação, Ciência e Tecnologia do Ceará - Campus de Quixadá. E-mail: oliveira.angelo@ifce.edu.br

2 Doutora em Educação pela Universidade Federal do Ceará (UFC). Professora do Instituto Federal de Educação, Ciência e Tecnologia do Ceará - Campus de Quixadá. E-mail: adele.araujo@ifce.edu.br
} 
characteristics which are adequated to the insertion of individuals at the competitive arena of the labor market. However, it is essential to oppose the neoliberal logic, so that the common school is understood as a space of all and for all, which eliminates the educational dualism that selects and excludes.Thereby, it is necessary to surpass the limits of the neoliberal context in order to effectively achieve the inclusive school.

Keywords: Schooling for people with disabilities. Mercadological Alignment. Neoliberal Context.

Resumen: Este artículo, de naturaleza bibliográfica, pretende discutir la inclusión escolar en interfaz con las determinaciones de la racionalidad neoliberal. Para ello, se ancla en las discusiones que trajeron autores como Silveira Bueno (2004), Rigo (2018) y Laval (2019), dados sus aportes al debate sobre la historia de la escolarización de las personas con deficiencia, a las reflexiones sobre el pensamiento neoliberal y a la relación entre inclusión escolar y neoliberalismo. Los resultados revelan que la inclusión escolar, desde la perspectiva neoliberal, funciona como un dispositivo de ajuste y normalización para la fabricación de características individuales aptas para la inserción de los individuos en la arena competitiva del mercado. Sin embargo, se entiende que es fundamental oponerse a la lógica neoliberal para que la escuela común se entienda como un espacio de todos y para todos y que elimina el dualismo educativo que selecciona y excluye. En este sentido, se hace necesario traspasar los límites del contexto neoliberal para llegar efectivamente a la escuela inclusiva.

Palabras-clave: Escolarización de personas con discapacidad. Mercadotecnia. Contexto neoliberal.

\section{Introdução}

Este artigo tem como objetivo fazer um paralelo discursivo entre a inclusão escolar e a ideologia neoliberal. Autores como Laval (2019), Rigo (2018) e Silveira Bueno (2004) balizaram a construção deste estudo bibliográfico por suas contribuições ao debate acerca da história da escolarização das pessoas com deficiência, às reflexões sobre o pensamento neoliberal e à relação entre inclusão escolar e racionalidade neoliberal.

Entender, pois, a lógica que orienta as relações sociais na atualidade e sua repercussão na organização da proposta pedagógica escolar é condição para explicitar as relações que se constroem no interior das próprias instituições de ensino, os projetos formativos e os interesses que os determinam.

Fazer uma análise sobre inclusão escolar e o neoliberalismo requer uma breve contextualização de como adentramos em uma crise estrutural. Consideramos a sistematização de Mészáros, o qual revela que a crise de ordem estrutural se diferencia de crises cíclicas, uma vez que aquela se particulariza por apresentar quatro pontos principais:

(I) seu caráter é universal, em lugar de restrito a uma esfera particular (por exemplo, financeira ou comercial, ou afetando este ou aquele ramo particular de produção, aplicando-se a este e não àquele tipo de trabalho, com sua gama específica de habilidades e graus de produtividade etc.); (2) seu alcance é verdadeiramente global (no sentido mais literal e ameaçador do termo), em lugar de limitado a um conjunto particular de países (como foram todas as principais crises no passado); (3) sua escala de tempo é extensa, contínua, se preferir, permanente, em lugar de limitada e cíclica, como foram todas as crises anteriores do capital; (4) em contraste com as erupções e os colapsos mais espetaculares e dramáticos do passado, seu modo de se desdobrar poderia ser chamado de rastejante, desde que acrescentemos a ressalva de que nem

Olhar de professor, Ponta Grossa, v. 24, p. I-15, e-18109.088, 2021.

Disponivel em <https://revistas2.uepg.br/index.php/olhardeprofessor> 
sequer as convulsões mais veementes ou violentas poderiam ser excluídas no que se refere ao futuro: a saber, quando a complexa maquinaria agora ativamente empenhada na 'administração da crise' e no 'deslocamento' mais ou menos temporário das crescentes contradições perder sua energia (MÉSZÁROS, 20II, p. 795-796).

A crise estrutural, ratificada desde a década de 1970, se estabeleceu nos países periféricos, como é o caso do Brasil, sobretudo a partir da década de 1990, quando tivemos uma conjuntura neoliberal que instituiu reformas na educação orientadas pelo Banco Mundial. Vejamos tal panorama histórico apresentado por Leher (1999, p. 26):

Na década de 1970, esta instituição considerava o financiamento às escolas primárias e secundárias de formação geral um contrassenso, defendendo o ensino técnico e profissional, modalidades tidas como mais adequadas às necessidades (presumidas) dos países em desenvolvimento. Na virada neoliberal da década de 1980, a orientação educacional do Banco sofreu uma inflexão em direção ao ensino elementar. A orientação anterior foi, então, duramente atacada como voluntarista e dispendiosa. $\mathrm{Na}$ década de 1990, a inflexão neoliberal não apenas permanece válida como é radicalizada.

Como podemos perceber, as reformas educacionais vão abarcar a educação elementar, levando em conta a lógica da educação mínima, já que o mais perfeito remédio para as mazelas sociais, sobretudo para as adversidades que provêm do desemprego estrutural, é proporcionar uma educação elementar. Nesse engodo, fica a cargo da educação "[...] operar as contradições da segregação, propiciando aberturas para o futuro" (LEHER, 1999, p. 29), de modo que a educação possa vislumbrar as possibilidades mínimas diante de políticas educacionais ínfimas.

De acordo com a perspectiva de Laval (2019), o neoliberalismo vem a ser uma racionalidade política mundial que consiste em se impor, pelos governos - não apenas na economia, mas na sociedade e nas subjetividades -, um mesmo funcionamento que podemos chamar de lógica do capital. Em outros termos, uma maneira de fazer com que as pessoas se comportem entre si, em suas relações sociais, de modo ajustado com a dinâmica do capitalismo. Esses comportamentos implicam competitividade, meritocracia e empreendimento de si (LAVAL, 2019).

Nesse contexto, o capitalismo saiu de sua esfera estritamente produtiva e financeira. Essa variante nos torna dominados por formas de vida que se aparentam na forma que o capitalismo impõe. Essa racionalidade política tem dois principais aspectos: I) a lógica da concorrência, que se torna o princípio de vida da sociedade; 2 ) e o modelo de empresa, que se impõe a todas as instituições mediante determinados dispositivos precisos e concretos, como a nova gestão pública, no caso das instituições do Estado (LAVAL, 2019).

Nesse sentido, é inegável que a escola venha cada vez mais incorporando o modelo competitivo-empresarial, que reverbera tanto no relacionamento entre os sujeitos aprendentes quanto 
na relação competitiva entre as unidades escolares. No interior dos sistemas de ensino, as regras passam a atender às normas de mercado, entre as quais se destacam definições de metas, indicadores de qualidade, competitividade, proatividade, gestão por competência, entre outras (RIGO, 20I8). Atravessados pela lógica mercadológica da competição, os sistemas de ensino concretizam, em sua oferta pedagógica, a ideia do mérito na condição de fundamento que sustenta o indivíduo como máxima unidade de desenvolvimento a ser perseguida nos processos formativos. Nessa perspectiva, cada sujeito, individualmente, é o grande responsável por seu sucesso e inserção nos mais altos patamares de um mercado aberto a todos, indistintamente (RIGO, 2018).

$\mathrm{E}$, sendo o indivíduo a unidade para a qual se destinam os processos educativos, o modelo de educação em que se transmitem os conteúdos sistematizados historicamente não é suficiente para atender às demandas do mercado. Mais do que conteúdos escolares, é necessário um conjunto de habilidades e competências que garantam, em última instância, a performance e o desempenho requeridos pelo mercado. Nesse perfil, incluem-se aptidões como: competitividade, proatividade, desenvoltura, poder de persuasão e empreendedorismo de si. Podemos destacar o que é proposto pela Base Nacional Comum Curricular (BNCC), que, nas orientações propostas no documento, assevera ser necessário desenvolver habilidades por meio de competências. Segundo o documento:

$\mathrm{Na}$ BNCC, competência é definida como a mobilização de conhecimentos (conceitos e procedimentos), habilidades (práticas, cognitivas e socioemocionais), atitudes e valores para resolver demandas complexas da vida cotidiana, do pleno exercício da cidadania e do mundo do trabalho (BRASIL, 20I7, p. 8).

Desse modo, compreendemos que escola não é o espaço para apreender o que foi historicamente sistematizado pela humanidade. A escola que tem o seu aparato no Estado e se atrela, preponderantemente, às necessidades do mercado visa admitir a demanda unilateral mercadológica, oferecendo um conhecimento minimizado com vistas ao atendimento ao mundo do trabalho - vale ressaltar, precarizado. Para Leher (1999, p. 26-27), o trabalho, em países da ordem periférica do capital:

[...] é condizente com o modo como estas nações estão inseridas na economia mundial: de forma subordinada, periférica, restrita a mercadorias de baixo valor agregado. $O$ trabalho requerido por uma economia nestes termos é pouco qualificado. A premissa econômica básica é que um mercado global livre decide melhor quais trabalhos estão localizados em que país. Em suma, melhor do que a análise endógena dos sistemas de ensino, a tese das 'vantagens comparativas' explica as prioridades educacionais em curso nas periferias.

Nessa direção, todos devem ter as habilidades mínimas para competir nessa arena comercial. As diferenças são aceitas na medida em que não ponham em risco o critério da competitividade, que, por sua vez, movimenta a engrenagem do mercado. Nesse cenário, o papel da escola na formação dos 
indivíduos se volta para ajustá-los aos marcos regulatórios do mercado. Nessa direção, a escola funciona como uma espécie de carpintaria que alinha e modela os sujeitos para exercerem sua função de perpetuar a ideologia e o funcionamento do grande mercado (RIGO, 20I8).

Assim, a inclusão escolar desponta como dispositivo por meio do qual todos deverão ser alcançados por uma formação que atenda aos ditames do mercado. Isso porque sua crescente necessidade de expansão demanda a existência de indivíduos capazes de "empreender-se" e expandirse para alimentar a voraz cadeia produtiva do mercado. Nesse sentido, há que se considerar os critérios que regulam a lógica do mercado e apontam para um padrão de homem e de mulher com competências e habilidades que garantam constante avolumamento e acúmulo do capital.

De modo contraproducente, acredita-se numa concepção de inclusão escolar que se opõe ao modelo neoliberal, pois tem a ver com outro modo de sociabilidade, visto que se ancora na colaboração entre os agentes envolvidos no processo educativo e considera as singularidades sem a pretensão de anulá-las. Trata-se de uma concepção de educação que se vincula a um projeto societário em que as diferenças são compreendidas como fator de complementaridade, de modo a eliminar barreiras e impedimentos à participação de todos nos diferentes espaços e decisões que implicam a vida em sociedade.

Tal perspectiva de ser humano, de mundo e de sociedade se materializa no cotidiano escolar e nas práticas de ensino, de modo a garantir que todos os estudantes construam aprendizagens ativas e participem plenamente da vida escolar. Aqui chamamos de aprendizagens ativas aquelas em que $\circ$ sujeito protagoniza a gestão dos processos de aquisição do conhecimento sem necessitar abrir mão de suas características, formas e estilos de aprender.

\section{Neoliberalismo: algumas considerações}

Embora existam diferentes concepções de neoliberalismo, de um modo geral, podemos compreendê-lo como uma visão de ser humano e de sociedade que ressalta as liberdades individuais como premissa basilar que sustenta a lógica e a soberania do mercado. Por essa razão, demanda a primazia do indivíduo como unidade por meio da qual se viabilizam as disputas que produzem e movimentam a engrenagem mercadológica. De acordo com Holanda (1998, p. 5I), “[...] o neoliberalismo é uma concepção de mundo surgida no início do século $X X$ contra a predominância das políticas estatizantes de influência socialista, das políticas socialistas e das políticas socialdemocráticas de influência Keynesiana".

Tal perspectiva de mundo altera as relações sociais de modo a criar uma realidade concreta e material que produz modos de ser e estar no mundo. Isso implica a constituição de uma sociabilidade 
que tem na economia a causa primeira, a pedra angular. Essa ordem impacta a vida do planeta e as múltiplas relações construídas pelo conjunto das mulheres e dos homens. Nesse sentido, a economia regida pelos ditames do mercado impõe um projeto societário que demanda a existência de um determinado tipo de ser humano dotado de subjetividades aptas à competição. Assim:

Como concepção de mundo, o neoliberalismo implica numa visão de homem, do agir humano e de sociedade. Portanto, polemizar com ele é problematizar sobre as condições de existência humana em meio à crise da racionalidade moderna. Restringir o debate na particularidade do mercado ou do Estado, ou ainda mercado versus Estado, sem discutir a função que uma ordem econômica tem a cumprir na vida humana é perder de vista o horizonte da totalidade (HOLANDA, 1998, p. 52).

A produção de subjetividades no contexto neoliberal está relacionada a um conjunto de ideologias que reforçam o individualismo. Assim, o sujeito é compreendido como uma unidade independente e apartada da realidade histórica e cultural na qual se desenvolve. Sendo assim, o indivíduo é o único responsável pela produção de seu destino, ou seja, suas conquistas dependerão única e exclusivamente de seu esforço, trabalho e empenho. Logo, o princípio do individualismo é uma das bases estruturais que sustentam a ideologia neoliberal, pois, de acordo com essa óptica, a cada indivíduo é dada a capacidade de competir na arena do mercado, em condições de igualdade.

Essa perspectiva de compreensão de ser humano apartada da realidade sócio-histórica se vincula à ideia do mérito. Isso porque, de acordo com essa visão, o sucesso a ser alcançado depende exclusivamente do indivíduo, desconsiderando as desigualdades de oportunidades. É, pois, o indivíduo, por meio de seus esforços, o único responsável por seu próprio sucesso ou fracasso. Assim, todos são chamados a empreender-se, a tornar-se uma espécie de empresário de si. E, nessa arena competitiva, são convidados a adquirir vantagens sobre seus oponentes, que, de igual modo, disputam essa corrida em que vencem os "mais fortes", "os mais capazes", "os mais esforçados" e os que melhor se adaptam às demandas do mercado.

A lógica neoliberal desconstrói a ideia do indivíduo como ser social. $\mathrm{Na}$ verdade, a compreensão neoliberal defende a inexistência da sociedade em seu caráter orgânico, produtor de cultura e história. $O$ indivíduo é a unidade constitutiva da sociedade, que, por sua vez, é apenas uma produção do conjunto de indivíduos que - livres dos efeitos sociais - se organizam para promover as condições de vida dos sujeitos e garantir melhores condições para o desenvolvimento das individualidades. Partindo desse prisma, a sociedade seria apenas um agente propiciador dos ideais individuais. Logo:

O indivíduo vive e age em sociedade. No entanto, a sociedade em si não existe, a não ser através das ações individuais. Somente no sentido em que o ser humano nasce em um ambiente organizado é que, para os neoliberais, se pode aceitar de 
forma lógica e histórica a concepção de que a sociedade antecede o indivíduo. A sociedade é o grande meio para atingir todos os fins (HOLANDA, 1998, p. 54).

Em uma sociedade regida pelas concepções neoliberais, o mercado ganha vida própria, captura os indivíduos e os transforma em peças de sua engrenagem. Como uma "mão invisível”, o mercado é aquele que rege as atividades individuais, levando os sujeitos a pensarem que as demandas do mercado são suas próprias necessidades. Nesse movimento, “[...] ○ mercado, única possibilidade de coordenação, é apresentado como o mecanismo que por si só coloca em ordem todo o sistema social, dando-lhe sentido e significado. $O$ mercado é o ponto para onde convergem e de onde irradiam as atividades dos indivíduos" (HOLANDA, 1998, p. 58).

O projeto neoliberal se opõe às intervenções do Estado como promotor de políticas públicas voltadas ao acesso e à socialização de bens e serviços para a promoção de equidade e bem-estar social. Nessa perspectiva, os serviços que são compreendidos como direitos, ofertados por meio de agências, empresas públicas e outros equipamentos estatais, são considerados ineficientes e incapazes de promover condições equiparadas de oportunidades. Assim, o Estado deve se reduzir à condição de regulador e garantidor das condições ideais para que a iniciativa privada se encarregue de ofertar seus produtos e serviços.

A consolidação do projeto neoliberal pressupõe a criação e a difusão de ideologias que obscureçam a retirada de direitos dos trabalhadores em substituição à "mercadorização" dos serviços antes ofertados pelo Estado. Na visão de Apple (2005, p. 32), “[...] não se trata de um processo simples esse de transformar a parte de nossas vidas e as instituições que não foram totalmente integradas às relações de mercado, a fim de que passem a fazer parte de um mercado". Assim, o autor aponta pelo menos quatro componentes que devem ser atingidos para darem sustentação à proposta neoliberal:

O redimensionamento dos bens e serviços para que sejam comprados e vendidos, ou seja, a ideia de que a qualidade dos produtos e serviços passa necessariamente pela lógica do mercado.

$\checkmark$ Os usuários que recebem os serviços do Estado devem estar convictos de que a melhor opção é comprá-los. É necessário, pois, construir desejos.

$\checkmark \quad$ As concepções e as condições de trabalho daqueles que integram empresas, agências ou instituições públicas devem ser substituídas por uma visão empresarial. Devem se alinhar com a lógica produtiva, competitiva e meritocrática, como rege o mercado.

Olhar de professor, Ponta Grossa, v. 24, p. I-15, e-18109.088, 2021.

Disponível em <https://revistas2.uepg.br/index.php/olhardeprofessor> 
$\checkmark$ A configuração neoliberal impõe a redução do Estado, cedendo lugar ao protagonismo da iniciativa privada. Ao converterem-se em negócios, os riscos gerados por esses empreendimentos devem ser sustentados pelo governo.

Para melhor esclarecer os componentes sistematizados por Apple (2005), elaboramos um pequeno gráfico que sintetiza a configuração do modelo neoliberal, como podemos observar na figura I.

Figura I - Configuração do modelo neoliberal

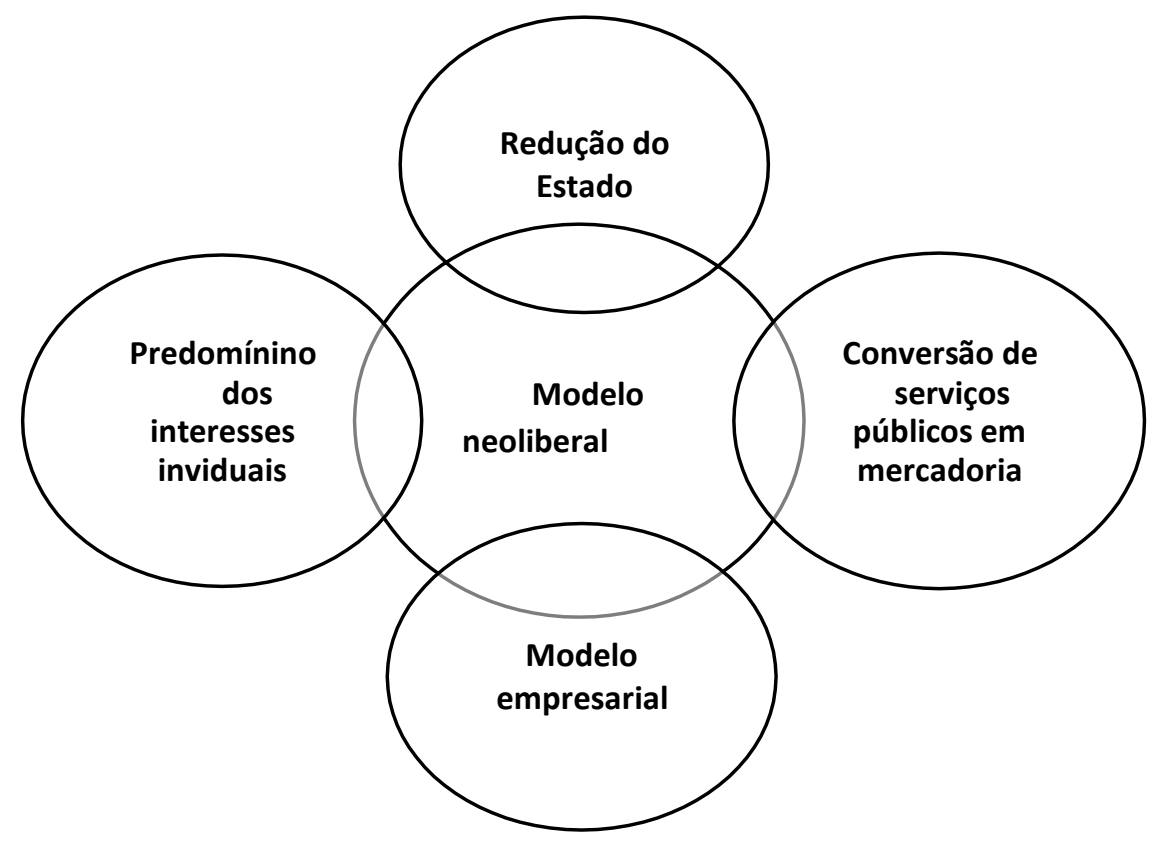

Fonte: Elaboração própria, 202I.

Nesse sentido, o mercado seria o grande meio a partir do qual devem circular as riquezas de uma nação. Serviços compreendidos como direitos, entre eles educação e saúde, transformam-se em mercadoria, cabendo a todos, indistintamente, a responsabilidade de se enquadrar na lógica do mercado para terem satisfeitas as suas necessidades. No tocante à educação, Laval (2004, p. 94, grifo do original) adverte que:

O neoliberalismo, de forma geral, contesta a ingerência do Estado na produção de bens e serviços, quer se trate de saúde, transporte ou educação. É a intervenção em si do Estado na oferta de ensino que é colocada em questão do modo mais radical, o que não impede, bem ao contrário, de se prever que, necessariamente, a demanda em termos de educação de base seja solvível. Segundo a doutrina, não há qualquer razão para que os benefícios que se podem esperar do mercado e da concorrência, em particular no tocante à performance, não possam ser esperados também no domínio da escola, onde despesas tão consideráveis estão em jogo. 
No modelo neoliberal, o eixo gravitacional em torno do qual circundam as instituições é a economia. Não obstante, a escola passa a materializar, em sua proposta formativa, o padrão empresarial. Tais processos envolvem o desenvolvimento de competências e habilidades demandadas pelo mercado, que incluem a apropriação do conhecimento tanto em sua esfera técnica quanto na comportamental. $O$ ideal de homem e de mulher é aquele capaz de perceber-se como uma empresa (apta a competir), de oferecer-se na condição de serviço e produto e, mais ainda, de ter canalizada toda a sua energia para os mais altos riscos que envolvem o processo de empreender. Laval (2004, p. 3) reforça que:

O novo modelo escolar e educativo que tende a se impor está fundamentado,
inicialmente, na sujeçãa mais direta da escola em razão da economia. Ele depende
de um 'economismo' aparentemente simplista cujo axioma principal é que as
instituições, em geral, e as escolas, em particular, só têm sentido dentro do serviço
que elas devem prestar às empresas e à economia. O 'homem flexível' e o
'trabalhador autônomo' constituem, assim, as referências do novo ideal pedagógico.

Alinhada com a ideologia neoliberal, a escola forma para a inserção do sujeito no mundo empresarial, que tem como pré-requisito a apropriação de características como adaptabilidade, flexibilidade e maleabilidade. Entretanto, esse perfil formativo não envolve a construção do potencial crítico do sujeito para que se torne capaz de refletir sobre a realidade que o rodeia. $O$ indivíduo neoliberal tem no livre-comércio, na iniciativa privada, no individualismo e na competição a esteira ou o motor do desenvolvimento, desprezando qualquer possibilidade de ruptura com esse projeto societário.

\section{Os destoantes da norma: diferentes modos de incluir/excluir}

A história da escolarização das pessoas com deficiência, assim como outras narrativas sóciohistóricas, é apresentada a partir de um discurso evolucionista. Ou seja, o evolucionismo é um modo de conceber a história como uma linha sucessiva de acontecimentos, numa tendência crescente de progresso e aperfeiçoamento. Nessa perspectiva, é quase parada obrigatória para os estudiosos da educação especial o conhecimento dos paradigmas sociais que atravessaram a história das pessoas com deficiência no mundo. Em linhas gerais, temos os paradigmas de segregação, exclusão, integração e, finalmente, o da inclusão.

Numa linha crescente de compreensão desses tempos históricos, cria-se uma narrativa do que seria a relação da sociedade para com as pessoas com deficiência. Na Idade Antiga, por exemplo, esses indivíduos eram mortos por não atenderem ao ideal de humanidade almejado. Já na Idade Média, quando a Igreja assume o poder político, ideológico, filosófico e econômico, o olhar social para com 
as pessoas com deficiência era atravessado pela perspectiva teológica. Logo, a transgressão era corrigida com o isolamento desses indivíduos em espaços como os mosteiros.

$\mathrm{Na}$ conhecida Modernidade, as pessoas com deficiência passaram a viver no seio de suas famílias, porém privadas de qualquer participação social. Mais recentemente, na década de 1980, o movimento de integração ganha força no mundo. Trata-se de uma inserção condicional desses indivíduos nos espaços sociais, desde que se ajustassem aos padrões preestabelecidos. Para Rigo e Naujorks (2016, p. 220), “[...] a história mostra-nos o quanto a humanidade esteve preocupada com a sua segurança, controlando e isolando minorias indesejáveis e as colocando à margem, para evitar o perigo da desordem social".

Seguindo a mesma linha evolutiva, nos anos 1990, o modelo da inclusão se difunde como possibilidade de que todos os espaços sejam acessíveis, garantindo a permanência e a participação, com respeito às singularidades na pluralidade da existência humana. Como podemos ver, o discurso oficial da história das pessoas com deficiência destaca o caráter progressivo-evolutivo no trato com esses indivíduos.

Tais narrativas deixam de lado a relação desse fenômeno com as determinações de cada tempo histórico, obscurecendo as mediações e condicionantes econômicos, políticos, ideológicos, bem como a concretude das relações sociais de cada tempo histórico, que engendram a produção social da deficiência. Na perspectiva de Silveira Bueno (2004, p. 72, grifos do original):

Essas interpretações sobre o percurso histórico dos excepcionais e da educação
especial reproduzem, por um lado, o cientificismo neutro que separa tanto os
primeiros quanto a segunda da construção histórica da humanidade, na medida em
que a excepcionalidade é vista como uma característica estritamente individual,
diferente da espécie, enquanto que a educação especial se confina ao esforço da
moderna sociedade democrática de integração desses 'sujeitos intrinsecamente
diferentes' ao meio social. Por outro lado, é fragmentada e descontextualizada, na
medida em que não os correlacionam nem com o desenvolvimento da educação em
geral, muito menos com as transformações sociais, políticas e econômicas por que
passaram as diversas formações sociais.

Desse modo, destaca-se a importância de se compreender os processos de escolarização das pessoas com deficiência, pois podem ser utilizados como instrumentos geradores para a explicitação do fenômeno social da deficiência em relação à totalidade das relações sociais. Como foi falado anteriormente, a história das pessoas com deficiência remonta a um passado de violência, segregação e abandono. E, mais do que isso, remonta a uma síntese das múltiplas determinações e da concretude de um tempo histórico. Para Marx (1986, p. 37):

Não se parte daquilo que os homens dizem, imaginam ou representam, e tampouco dos homens pensados, imaginados e representados para, a partir daí, chegar aos homens de carne e osso; parte-se dos homens realmente ativos e, a partir de seu 
processo de vida real, expõe-se também o desenvolvimento dos reflexos ideológicos e dos ecos desse processo de vida.

Nesse passado de segregação extrema, as diferenças eram eliminadas como forma de poupar a sociedade do infortúnio da convivência com os chamados "desviantes". Com o advento da nova ordem capitalista, emergiu a necessidade de enquadramento daqueles que fugiam da norma para atender às demandas do modo de produção econômico em ascensão. Para Silveira Bueno (2004, p. 63), “[...] o desenvolvimento da sociedade capitalista se baseia na homogeneização para a produtividade que perpassará toda a história da educação especial".

No instante da criação das instituições de ensino especializado, inicialmente para cegos e surdos, a burguesia em ascensão tentou solucionar estrategicamente dois contratempos: tirar de circulação os degenerados, que eram tidos como um peso para a nova configuração social e econômica, e, por outro lado, torná-los aproveitáveis e lucrativos ao capitalismo (SILVEIRA BUENO, 2004).

Assim, a educação especial, no formato separatista e substitutivo da escola comum, por mais que se apresente como um direito que alcança o sujeito em suas particularidades, dada a suposta incapacidade de se enquadrar na lógica do chamado "mundo normal", esconde a sua função primeira em uma sociedade capitalista, que é legitimar as desigualdades e selecionar os indivíduos através de parâmetros e referenciais centrados na produtividade e no lucro. Por isso, "[...] a ampliação da educação especial, por trás da igualdade de direitos, oculta a função fundamental que tem exercido nas sociedades capitalistas modernas: o de instrumento de legitimação da seletividade social" (SILVEIRA BUENO, 2004, p. 80).

Diante das questões discutidas anteriormente, como a inclusão escolar participa desse novo espírito do capitalismo? De acordo com Lopes (2009), antes do século XVIII, os considerados desviantes eram submetidos a um regime de reclusão excludente. Esse modo de lidar com os "anormais" se ancorava na necessidade de manter distantes os então "perturbadores" da ordem.

Do século XVIII em diante, as demandas da nova ordem econômica em ascensão ressignificaram a relação com os espaços separatistas, que, até então, funcionavam apenas para manter distantes os degenerados. Constrói-se, a partir dali, “[...] uma aproximação das instituições que poderiam atuar produtivamente sobre esses sujeitos, de forma a recuperá-los pela inclusão. Chega-se, então, a uma "reclusão includente" (LOPES, 2009, p. 166).

$\mathrm{Na}$ atualidade, estamos diante do que poderíamos caracterizar como inclusão excludente. Isso porque aqueles que não conseguem atender às demandas do mercado produtivo são marginalizados no interior dos espaços ditos inclusivos. Nessa perspectiva, o imperativo da inclusão funciona até o ponto em que não se esgotam as possibilidades de ajustamento do sujeito à lógica do mercado. 
Aqueles, porém, que não encaixam suas singularidades no formato produtivo ficam restritos apenas à esfera do acesso aos espaços comuns, sendo-lhes vetada a possibilidade de participação. Fugindo de uma óptica evolutiva e linear de compreensão da realidade, o esquema da Figura 2 resume os modos (ainda não superados) como a sociedade vem se relacionando com sujeitos desviantes.

Figura 2 - Modos de incluir/excluir

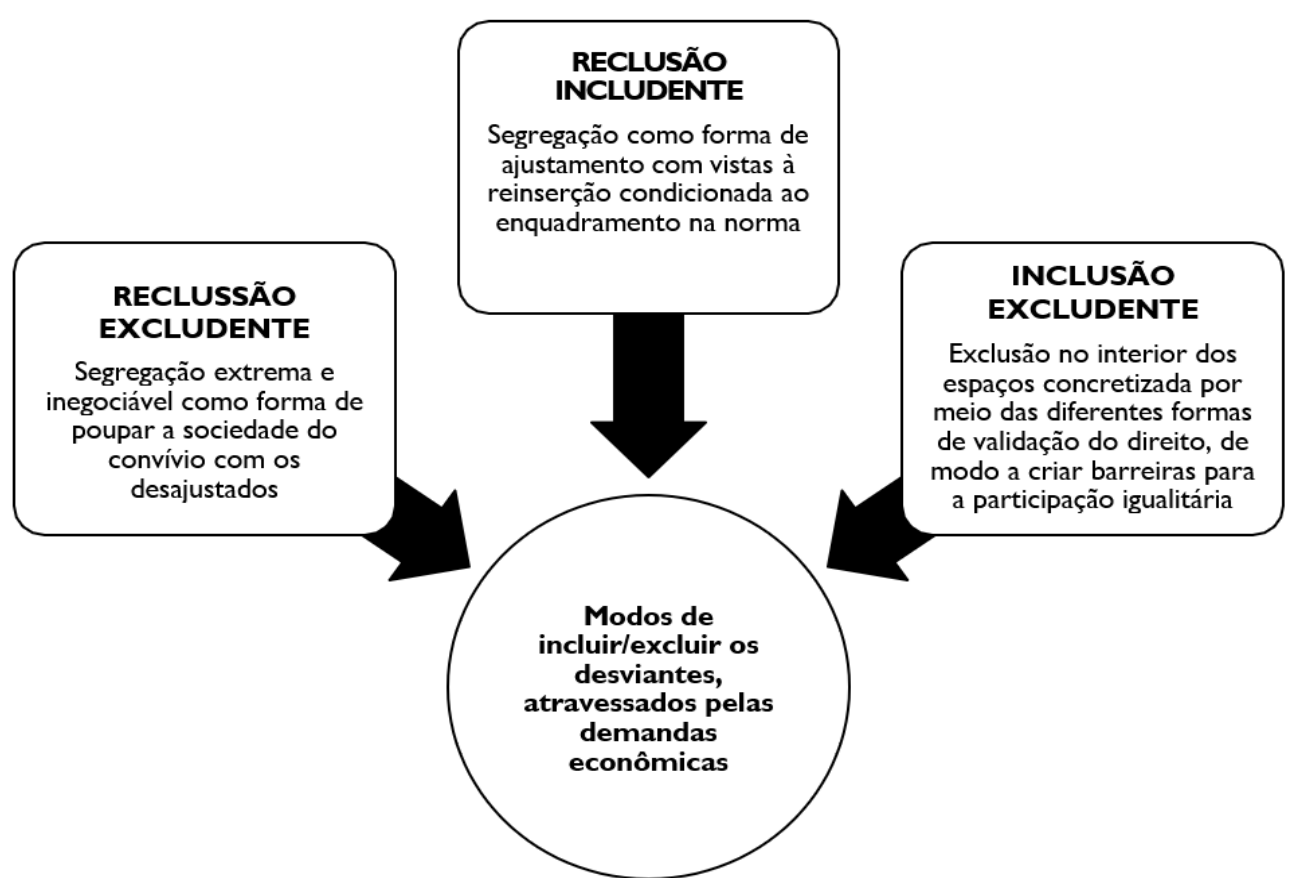

Fonte: Elaboração própria, 2021.

Entende-se, portanto, que os processos de ajustamento e normalização na atualidade atendem às demandas do neoliberalismo. Isso porque objetivam adequar o sujeito à apropriação de competências e habilidades que viabilizam a formação de um perfil competitivo alinhado à lógica do mercado dentro de um cenário alimentado pela circulação, pela troca e pelo acúmulo do capital.

\section{Inclusão escolar como dispositivo de ajustamento}

A escola, como espaço validado culturalmente para a transmissão dos saberes sistematizados, não se mantém apartada da realidade material e concreta de seu tempo histórico. Assim sendo, as instituições escolares reproduzem a cultura de um dado momento histórico. A oferta escolar é, pois, um território de disputas que, na óptica de Althusser (1980), reproduz as ideias da classe dominante. Nesse sentido, a inclusão escolar se concretiza como dispositivo que ganha vida por meio das atuais políticas públicas e passa a integrar a oferta escolar nos últimos anos. Assim, a educação inclusiva vem 
compondo os discursos oficiais de modo a abranger os sistemas de ensino nas esferas municipal, estadual e federal.

A compreensão de dispositivo abordada neste artigo se ancora nos estudos de Foucault (2006) e, por isso, apresenta-se como um agrupamento diverso que contempla instituições, regulamentos, leis, resoluções, orientações normativas, medidas administrativas, narrativas científicas e filosóficas, códigos de condutas morais, documentos oficiais e extraoficiais. Enfim, orientações explícitas e implícitas que, de algum modo, conduzem a trama que compõe uma determinada realidade. Logo:

Entendo dispositivo como um tipo de formação que, em um determinado momento histórico, teve como função essencial responder a uma urgência, por isso é eminentemente estratégico. $O$ dispositivo tem, portanto, uma função estratégica dominante. O dispositivo está inscrito num jogo de poder, estando sempre, no entanto, ligado a uma ou a configurações de saber que dele nascem, mas que igualmente o condicionam. É isto o dispositivo: estratégias de relações de forças sustentando tipos de saber e sendo sustentadas por eles (FOUCAULT, 2006, p. 246).

Se partimos da compreensão de que a inclusão escolar é um mecanismo de adequação ou reparação da questão da anormalidade, é possível chegarmos ao entendimento de que os processos educativos ofertados às pessoas com deficiências seguem exercendo uma função estratégica em uma sociedade hegemonicamente ancorada em padrões de normalidade.

Nessa mesma linha de raciocínio, o estabelecimento da inclusão escolar como modo de enquadramento e desenvolvimento de habilidades produtivas para que as pessoas com deficiência possam ocupar espaços no mercado de trabalho, atendendo aos ditames mercadológicos, pode ser compreendido como um dispositivo articulado junto à execução dos processos mercadológicos. Isso porque:

Se a inclusão escolar pode ser entendida como uma forma de evitar riscos e, ao mesmo tempo, desenvolver potenciais produtivos (sujeitos competitivos), como geralmente vimos nas justificativas para a inclusão; se há perspectivas de que as pessoas com deficiência possam ocupar um lugar no mercado de trabalho, então, ela pode ser compreendida como um dispositivo, confirmando o que Foucault nos diz, que um dispositivo se organiza a partir de um problema e de uma função estratégica (RIGO, 2018, p. 56).

Partindo do pressuposto anteriormente descrito, incluir seria uma forma de inserir o sujeito em uma dinâmica normativa para que desempenhe uma função estruturante no interior dos processos sociais. Essa dinâmica se vincula à trama social em sua totalidade e, como numa engrenagem, os processos se desdobram para um mesmo fim, a saber: a sustentação e a continuidade da estrutura social vigente. 


\section{Recomendações finais}

A partir do objetivo de se discutir a inclusão escolar em um paralelo com o neoliberalismo, foi possível compreender que a proposta da inclusão escolar pressupõe duas vertentes: uma que se vincula à racionalidade neoliberal e outra que rompe com o modelo capitalista de mercado na direção de um projeto social emancipatório.

Na perspectiva neoliberal, a lógica da normalização atende aos ditames do mercado, uma vez que todos, indistintamente, devem desenvolver competências e habilidades que garantam a participação no cenário competitivo do mercado. Esse perfil requerido aos indivíduos suscita a capacidade de disputa pela ocupação de espaços cada vez maiores na arena mercadológica, com base nas ideias de meritocracia, proatividade e senso de empreendedorismo.

Por outro lado, a proposta da inclusão escolar, que se contrapõe à lógica do capital, entende a escola comum como direito de todos e se concretiza por meio da participação e do acesso aos conhecimentos historicamente sistematizados pela humanidade. Nesse sentido, a educação escolar é um instrumento que contribui ativamente para o processo de humanização do conjunto dos homens e das mulheres e, por isso, defende a construção de uma escola unitária que supere o histórico dualismo educacional seletivo e excludente.

Portanto, é necessário refletirmos sobre o modo como a racionalidade neoliberal vem absorvendo o direito à escolarização das pessoas com deficiência nos espaços comuns socialmente validados para a transmissão dos saberes historicamente sistematizados. Nessa perspectiva, reduz os sujeitos a um padrão de normalidade que aprisiona as singularidades para atender às demandas do mercado por meio de competências e habilidades manifestas através da competitividade, da meritocracia e do empreendedorismo de si.

\section{Referências}

ALTHUSSER, L. Ideologia e aparelhos ideológicos do Estado. 3. ed. Lisboa: Presença, 1980.

APPLE, M. Para além da lógica do mercado: compreendendo e opondo-se ao neoliberalismo. Rio de Janeiro: DP\&A, 2005.

BRASIL. Base Nacional Comum Curricular. Brasília, DF: MEC, 2017.

FOUCAULT, M. Microfísica do poder. 22. ed. Rio de Janeiro: Graal, 2006.

HOLANDA, F. U. X. Do liberalismo ao neoliberalismo: o itinerário de uma cosmovisão impenitente. Porto Alegre: PUCRS, 1998. 
LAVAL, C. A escola não é uma empresa: o neoliberalismo em ataque ao ensino público. Londrina: Planta, 2004.

LAVAL, C. A escola não é uma empresa: o neoliberalismo em ataque ao ensino público. São Paulo: Boitempo, 2019.

LEHER, R. Um novo senhor da educação? A política educacional do Banco Mundial para a periferia do capitalismo. Outubro, São Paulo, v. I, n. 3, p. 19-30, 1999.

LOPES, M. C. Políticas de inclusão e governamentalidade. Educação \& Sociedade, Porto Alegre, v. 34, n. 2, p. 153-169, 2009.

MARX, K. A ideologia alemã. São Paulo: Hucitec, 1986.

MÉSZÁROS, I. Para além do capital: rumo a uma teoria da transição. São Paulo: Boitempo, 20II.

RIGO, N. M. Inclusão, diferenças e alteridade: a experiência no encontro com o outro. Curitiba: Appris, 2018.

RIGO, N.; NAUJORKS, M. A produtividade da racionalidade neoliberal na inclusão escolar: a história de Lucas. Linhas Críticas, Brasília, DF, v. 22, n. 47, p. 210-228, 2016. Disponível em: https://doi.org//0.265I//lc.v22i47.4853 Acesso em: 08. Dez. 202 I.

SILVEIRA BUENO, J. G. Educação especial brasileira: integração/segregação do aluno diferente. São Paulo: EDU, 2004.

Recebido em: 08 de junho de 2021 .

Versão corrigida recebida em: 08 de dezembro de 202I.

Aceito em: 09 de dezembro de 2021.

Publicado online em: 16 de dezembro de 2021.

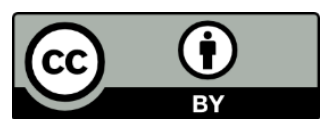

